www.jmscr.igmpublication.org

Index Copernicus Value: 79.54

ISSN (e)-2347-176x ISSN (p) 2455-0450

crossref DOI: https://dx.doi.org/10.18535/jmscr/v7i6.174

\title{
Unusual case of metastasis of urinary bladder Transitional cell carcinoma to the gingival
}

\author{
Authors \\ Dr Pritanjali Singh ${ }^{1}$, Dr Anju Singh ${ }^{2}$, Dr Vijaj Pratap Singh ${ }^{3}$ \\ ${ }^{1}$ Associate Professor, Dept of Radiation Oncology, All India Institute of Medical Sciences, Patna \\ ${ }^{2}$ Associate Professor, Dept of Pathology, Indira Gandhi Institute of Medical Sciences, Patna \\ ${ }^{3}$ Consultant Surgeon, Savera Cancer Hospital, Patna
}

\begin{abstract}
Metastasis to the oral cavity usually originates from the breast, lung or kidneys. Transitional cell carcinoma (TCC) of the urinary bladder rarely metastasizes to the gingiva. Here we present an interesting new case of gingival metastasis in a 65 year old male. The patient was in between treatment for recurrent urinary bladder cancer. He defaulted the same for three months due to personal reasons, and presented in the clinic with a left sided mandibular swelling. Clinical examination revealed left lower gingival lesion, the biopsy of which confirmed TCC.

Keywords: Oral cavity, Gingiva, metastasis, Transitional cell carcinoma.

Key Messages: In a patient with a known history of cancer, a gingival metastatic lesion although rare and an extreme possibility, has to be kept in mind.
\end{abstract}

\section{Introduction}

Oral cavity metastasis amounts to about $1 \%$ of all malignant oral cavity tumors ${ }^{[1]}$. The most common primary sites include the breast, lung, and renal cell carcinoma ${ }^{[2]}$.Transitional cell carcinoma is an inherently aggressive tumor with a high percentage of relapse rates. Metastasis to the oral cavity from urinary bladder is extremely rare and affect jawbones rather than soft tissues. Only four metastatic cases to the oral soft tissues (tongue, submandibular gland, upper alveolus, buccal mucosa) have been reported so $\operatorname{far}^{[3]}$. We report on a patient who had metastatic transitional cell carcinoma in the gingiva from urinary bladder.

\section{Case History}

A 65 year old male patient, chronic smoker for the last 25 years, was investigated for hematuria in
1991. He was diagnosed to have low grade transitional cell carcinoma of the urinary bladder Stage II. He underwent radiation therapy followed by chemotherapy thereafter which he was completely symptom free for the next 19 years. In December 2009 he presented again with hematuria. A Radiological examination by ultrasonography showed the bladder wall to be thickened and a mixed echogenic - broad based growth approximately $6 \mathrm{~cm}$ by $7 \mathrm{~cm}$ with surface calcification, situated on the left posterior- lateral wall of urinary bladder and prostatic urethra. Cystoscopy confirmed the fore mentioned findings along with involvement of prostatic urethra. The patient underwent transurethral resection of the tumor. The histopathology confirmed Transitional cell carcinoma WHO grade II, with tumor involving the smooth 


\section{JMSCR Vol||07||Issue||06||Page 1043-1046||June}

muscles. A metastatic workup was done which showed disease to be confined to the urinary bladder. The patient was advised to undergo radical cystectomy to which he refused. Hence he was put on salvage chemotherapy after repeat TURBT. He received 2 cycles of gemcitabine $1000 \mathrm{mg} / \mathrm{m} 2$ and carboplatin AUC 5 after which he defaulted for three and a half months due to financial constraints. Following thereafter he presented to the clinic with complaints of swelling left lower jaw, pain on chewing, excessive salivation with halitosis and occasional bloodtinged saliva since 15 days [Figure-1]. He was evaluated and diagnosed to have a mass lesion in left lower alveolus approximately $2 \times 1.5 \mathrm{~cm}$ in size [Figure -2] .The CT scan did not reveal any bony involvement [Figure -3]. A biopsy revealed nests of carcinomatous cells with papillary processes lined by transitional epithelium 10-12 cell thick. The cells were mildly pleomorphic and nuclear polarity was focally lost. Mitosis was occasionally seen. The overall picture was consistent with transitional cell carcinoma grade II [Figure-4]. The patient was planned and started on radiotherapy to the head and neck followed by completion of the previously started chemotherapy regimen. He was symptom free for two and a half years after which he developed multiple skeletal metastases and ultimately succumbed.

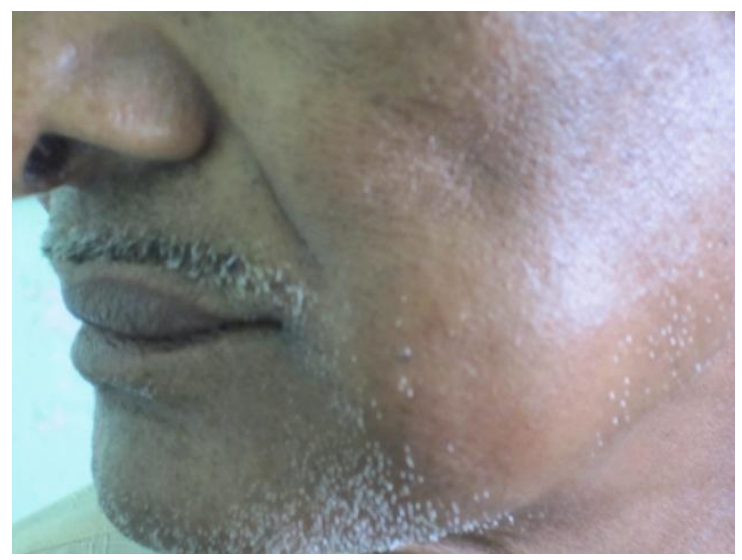

Figure 1: Obvious jaw swelling

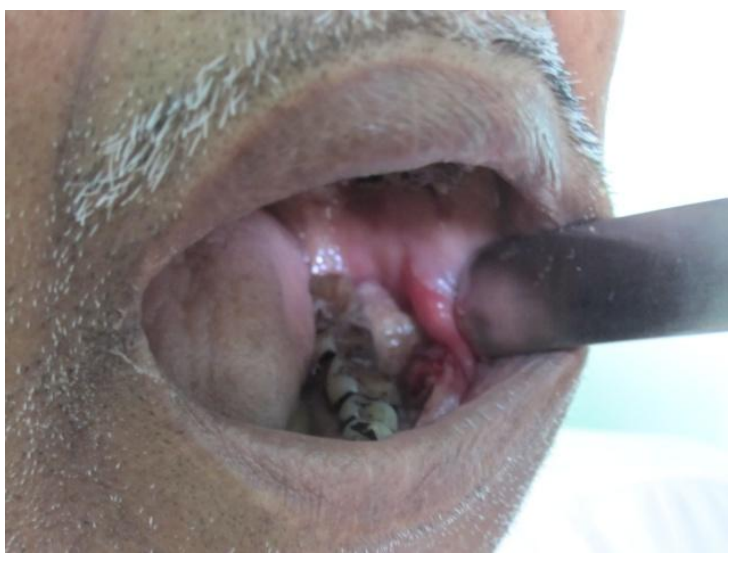

Figure 2: Irregular mass lesion in left lower gingivo-buccal sulcus

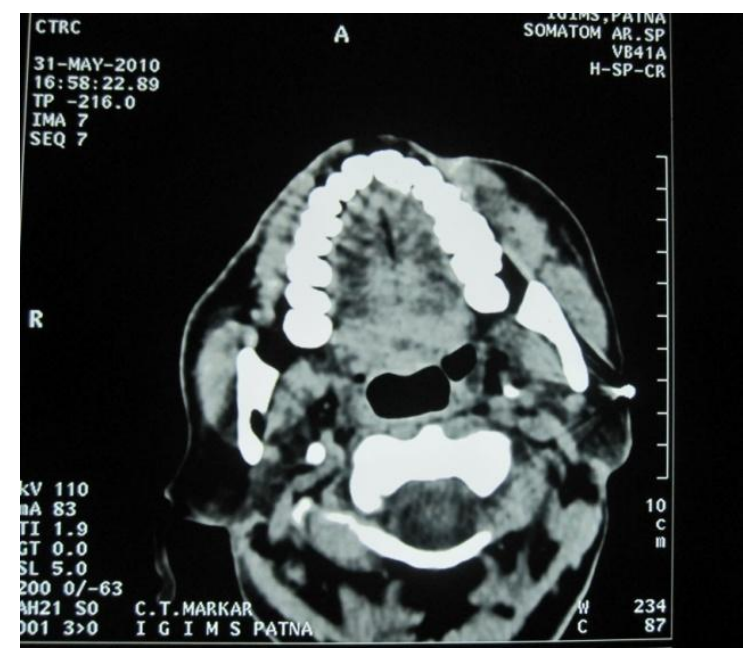

Figure 3: Radiological examination.

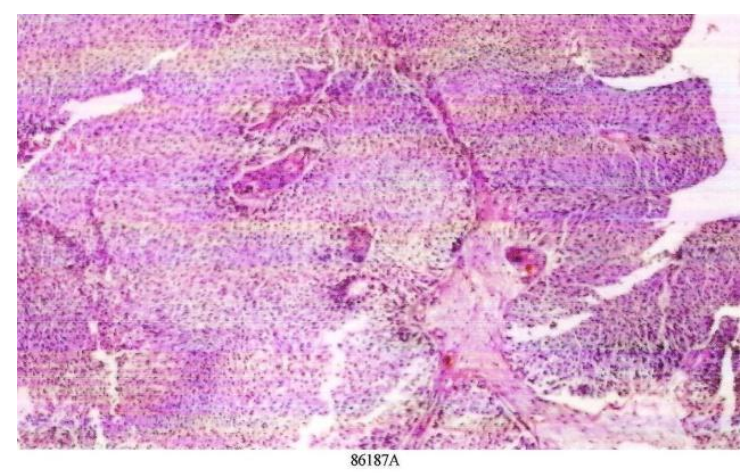

Figure 4: Histological features of transitional cell carcinoma

\section{Discussion}

The burden of urinary bladder cancer varies with estimates of approximately 383,000 cases worldwide $^{[4]}$.Usual sites of metastasis from TCC of the urinary bladder include lymph nodes (78\%), followed by liver $(38 \%)$ and lung $(36 \%)$, bone $(27 \%)$, adrenal $(21 \%)$ and intestines $(13 \%)^{[5]}$. 
Metastatic tumors to the oro-facial region account for approximately $1-1.5 \%$ of all malignant oral tumors, with most of them effecting the jawbone. Metastasis to the oral cavity soft tissue from urinary bladder is extremely rare ${ }^{[1]}$. Only four cases of cancer confined to the oral soft tissues with no bone involvement have been reported so far ${ }^{[3]}$. The mode of spread to the head and neck region bypassing the abdomen and the thorax is not well understood. It has been postulated that tumor infiltration of the venous plexuses of the bladder and prostate may be implicated. These plexuses are thin walled, have very few valves and may be responsible for metastatic spread via the vertebral venous plexus to the head and neck region. Moreover the oral soft tissues have a rich network of capillaries which can entrap malignant cells $^{[6]}$. Metastasis of squamous cell carcinoma (scc) from oral cavity to urinary bladder has also recently been reported enforcing a probable site specific causal pathogenesis which needs to be studied further ${ }^{[7]}$. The metastatic lesions of the oral soft tissues usually manifests as a submucosal mass as was appreciated in our case; and very few cases present as ulcers ${ }^{[8]}$. The probability of a second primary especially in the background history of smoking was borne in mind but was ruled out by biopsy and histopathology. The treatment of such lessions depends on many factors including the metastatic workup and the performance status. An oral metastasis usually implies a serious prognosis, as most patients present multiple organ involvement at the time of diagnosis, with the average survival time being a few weeks or months. However if the primary tumour is controlled and the patient's medical condition permits the metastatic disease should be aggressively treated so as to attain a reasonable symptom free interval. On review of literature we found the first case of TCC of urinary bladder which presented with an alveolar metastases was a 58 year old male of Indian origin with wide spread disease who survived for only 5 months ${ }^{[8]}$. Whether this comparison holds any etiopathological significance is yet to be ascertained. Moreover our patient had a substantial symptom free interval of approximately two and a half years enforcing the need of aggressive treatment.

\section{Conclusion}

In a patient with a known history of cancer, a gingival metastatic lesion although rare and an extreme possibility, has to be kept in mind. Careful clinical examination, histopathological investigations and immunohistochemistry techniques are required to rule out second primary lesion since the treatment and prognosis will likewise change.

\section{References}

1. van der Waal RI, Buter J, van der Waal I. Oral metastases: Report of 24 cases. Br J Oral Maxillofac Surg. 2003; 41:3-6. [PubMed]

2. Nishimura Y, Yakata H, Kawasaki TT, Nakajima T. Metastatic tumors of the mouth and jaws. A review of the Japanese literature. J Oral Maxillofac Surg. 1982; 10:253-8. [PubMed]

3. Lee Kyu S, Song Ik C,Yun Hwan J , Jo Deog Y, Kim Samyoug, Lee Hyo J. Transitional cell carcinoma of urinary bladder metastatic to oral mucosa. Oncology Letters 3: 343-345, 2012.

4. "Bladder - Estimated incidence, all ages: both sexes". GLOBOCAN 2008: Estimated cancer Incidence, Mortality, Prevalence and Disability- adjusted life years (DALYs) Worldwide in 2008. International Agency for Research on Cancer (IARC), World Health Organization

5. Babaian RJ, Johnson DE, Llamas L, Ayala AG. Metastases from transitional cell carcinoma of urinary bladder. Urology. 1980; 16:142-144.

6. Hirshberg A, Leibovich P, Buchner A. Metastatic tumors to the jawbones: Analysis of 390 cases. J Oral Pathol Med. 1994; 23:337-41. [PubMed] 
7. Goel T, Reddy S, Thomas J, Gang S. Squamous cell carcinoma of the oral cavity with metastasis to the urinary bladder. Indian J Urol 2006 ; 22:372

8. Hirshberg A, Shnaiderman-Shapiro A, Kaplan I, Berger R. Metastatic tumours to the oral cavity-pathogenesis and analysis of 673 cases. Oral Oncol. 2008 44:743-52. [PubMed]

9. Doval DC, Naresh KN, Sabitha KS, Vijaykumar M, Bapsy PP, Anantha N and Kumarswamy SV: Carcinoma of the urinary bladder metastatic to the oral cavity. Indian J Cancer 31: 8-11, 1994. 